\title{
Overdenture with magnetic attachments for a patient with Parkinson's disease: a case report
}

\author{
Bo-Young Ma, Byung-Kwee Min, Hong-So Yang, Sang-Won Park, Hyun-Pil Lim*, Kwi-Dug Yun, Chan Park, \\ Jin-Ho Shin \\ Department of Prosthodontics, School of Dentistry, Chonnam National University, Gwangju, Republic of Korea
}

It is very hard for edentulous patients to satisfy retention and stability with their complete denture. Especially, for patients with systemic diseases such as Parkinson's disease causing involuntary and limited movements, fabricating complete dentures may be challenging to both dentists and patients due to functional limitations. To overcome this problem, overdentures can be used through conserving retained roots. In this case, a 45 -year-old male patient had to extract numerous teeth due to dental caries, and at the time of visit he was taking drugs for diabetes and Parkinson's disease for a period of long time. A complete denture was applied to maxilla, and for mandible, an overdenture on two preserved retained roots was applied where its retention and stability were obtained by magnetic attachments. This case reports that overdenture with retained roots improved overall functional limitations. (J

Dent Rehabil Appl Sci 2016;32(4):301-6)

Key words: Parkinson's disease; overdenture; magnetic attachment

\begin{abstract}
서론
고령화 사회로 접어들면서, 고령 및 전신질환을 보유한 환자들에서 의치와 같은 보철치료에 대한 수요가 증가하 고 있는 추세지만, 환자가 만족할 만한 의치의 유지와 안 정을 얻는 것은 많은 임상가에게 어려운 보철 치료 분야 로 인식되고 있다.

일반적으로 하악 무치악 환자들은 하악의 구조적인 특 성 및 혀로 인한 해부학적 한계로 총의치의 하중-지지 능 력 감소 및 부적절한 유지력을 보인다. ${ }^{1}$ 이러한 문제를 극 복하기 위해 남아있는 치근을 이용하거나 임플란트를 부 가적으로 이용하여 하악 총의치를 제작한다면, 지지, 유 지, 안정, 저작력을 향상시킬 수 있다. ${ }^{2}$

피개의치에 사용될 수 있는 유지 장치는 매우 다양하 며 환자와 관련된 요소, 술자의 능력, 경험도에 따라 선택
\end{abstract}

될 수 있다. 어태치먼트 선택 시 연결 여부에 따라 solitary type과 bar type으로 나눌 수 있다. ${ }^{3}$ Bar type의 경우, 안 정성이 우수하나 기공과정이 어렵고, 더 많은 악간 공간 이 요구되며, 고비용이라는 단점이 있다. Solitary type 어 태치먼트는 bar type 어태치먼트에 비해 다양한 방향으 로 의치의 움직임을 발생시킬 수 있다. Solitary type 어태 치먼트만으로도 충분히 환자의 요구를 만족시킬 수 있고 장기적으로 보아 큰 문제점이 보이지 않을 것이라 판단 된다면 최소한의 수직 공간을 요구하는 solitary 어태치 먼트를 선택하는 것이 더 효과적일 수 있다. ${ }^{1}$

본 증례는 파킨슨 병으로 인해 수조작에 불수의적 떨 림 및 운동제한이 있는 환자에게 상악 완전의치, 하악은 2 개의 잔존 치근에 자성 어태치먼트를 이용한 피개의치 로 수복한 증례이다. 


\section{증례 보고}

본 증례환자는 45 세 남성환자로 상, 하악 다수의 치아 에 우식, 파절 등으로 의치를 제작하고 싶다는 주소로 내 원하였다. 의과적 병력으로는 10년 전부터 당뇨병과 파 킨슨 병으로 약을 복용 중이었으며, 그로 인하여 불수의 적 떨림 및 운동제한이 관찰되었다.

임상검사 및 방사선 검사(Fig. 1, 2)에서 우식으로 인해 대다수의 치아를 발치해야 했고, 하악 좌측 견치, 우측 견 치는 우식 제거 후 국소의치를 위한 지대치로는 부적합

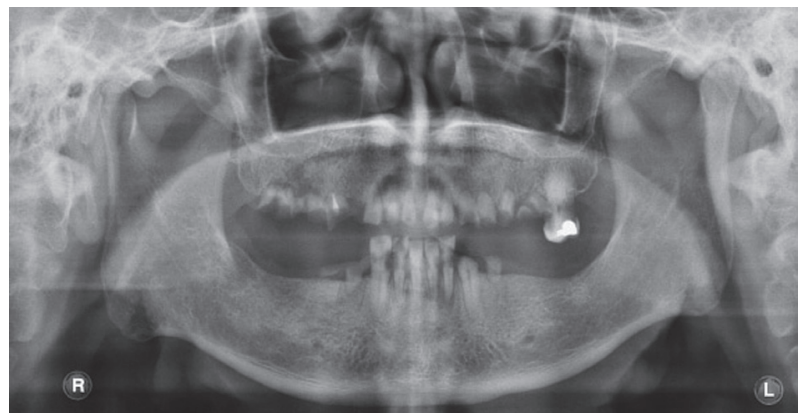

Fig. 1. Initial panoramic radiograph.
하다고 판단되어, 상악은 총의치, 하악은 좌측 견치, 우 측 견치 치근을 이용한 피개의치로 계획하였다. 파킨슨 병으로 인한 불수의적 떨림, 운동제한을 고려하여 하악 피개의치의 유지 장치로는 자성 어태치먼트를 선택했다.

다수의 치아를 발치 후 하악 좌측 견치, 우측 견치 우식 제거 후 근관 치료를 시행하였다. 치근의 높이는 keeper post를 가능한 낮은 위치로 설정하기 위해 주변 치은 보 다 약간 더 깊게 삭제하여 의치 제작에 요구되는 수직 적 공간을 확보했다. Keeper post 제작하기 위해 지대 치 preparation 후 polyvinyl siloxane (Honigum ${ }^{\circledR}, \mathrm{DMG}$, Hamburg, Germany)을 이용하여 인상채득을 하였다. 주모형 제작 후 keeper post를 위한 wax-up을 하였고, Magfit EX $600^{\circledR}$ (Aichi steel Co., Aichi, Japan)의 keeper 를 keeper carrier에 위치시킨 후 서베이어를 이용하여 부 착하였다. 주조, 최종 연마 후 keeper post를 완성하였으 며 구강 내 합착하였다(Fig. 3).

상악은 총의치, 하악은 치근 피개의치 제작을 위한 개인트레이를 제작하였고, 이 개인트레이를 이용하여 모델링컴파운드(Peri-compound, GC Corp., Tokyo, Japan)로 변연 형성 후 polysulfide (Permlastic ${ }^{\circledR}$, Kerr Manufacturing Co., Romulus, USA)로 최종 인상채득하
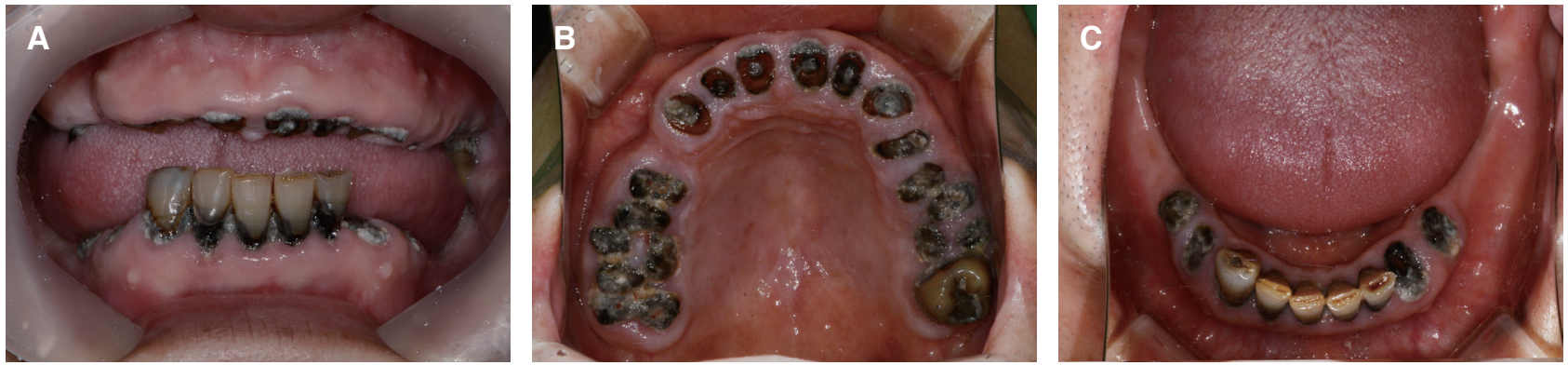

Fig. 2. Initial intraoral photographs. (A) Frontal view, (B) Maxillary occlusal view, (C) Mandibular occlusal view.
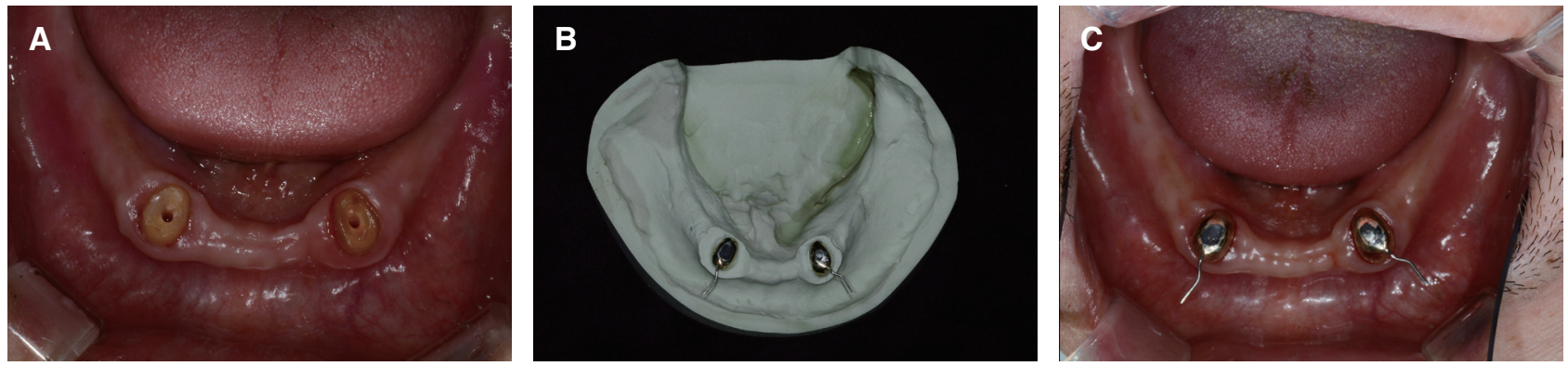

Fig. 3. Magfit EX 600. (A) Bare roots on Mandible, (B) Master cast with magnetic attachments, (C) Installed magnetic attachment. 

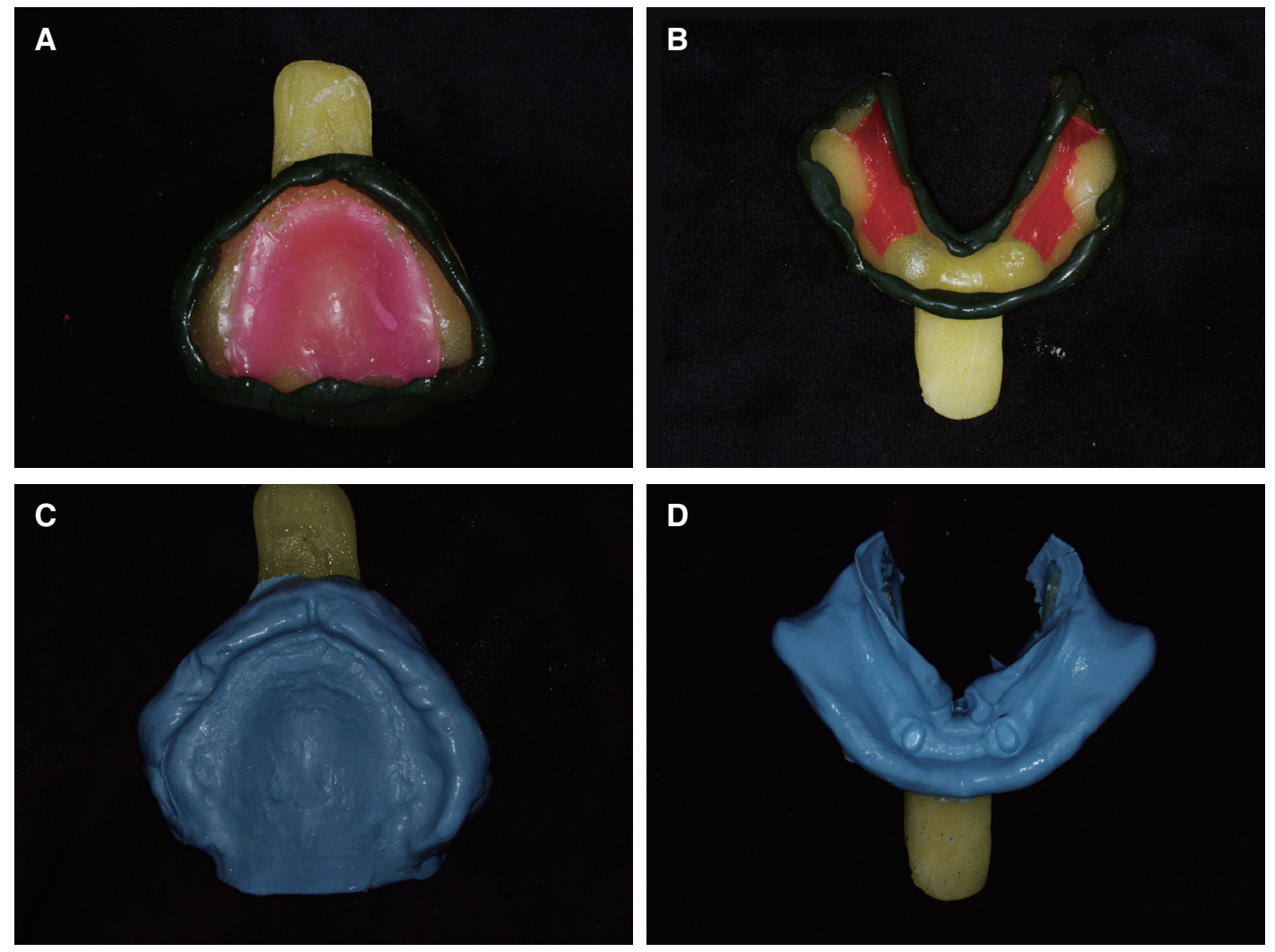

Fig. 4. Border molding and definitive impression taking. (A) Border molding for maxillary denture, (B) Border molding for mandibular denture, (C) Final impression taking of maxilla, (D) Final impression taking of mandible.
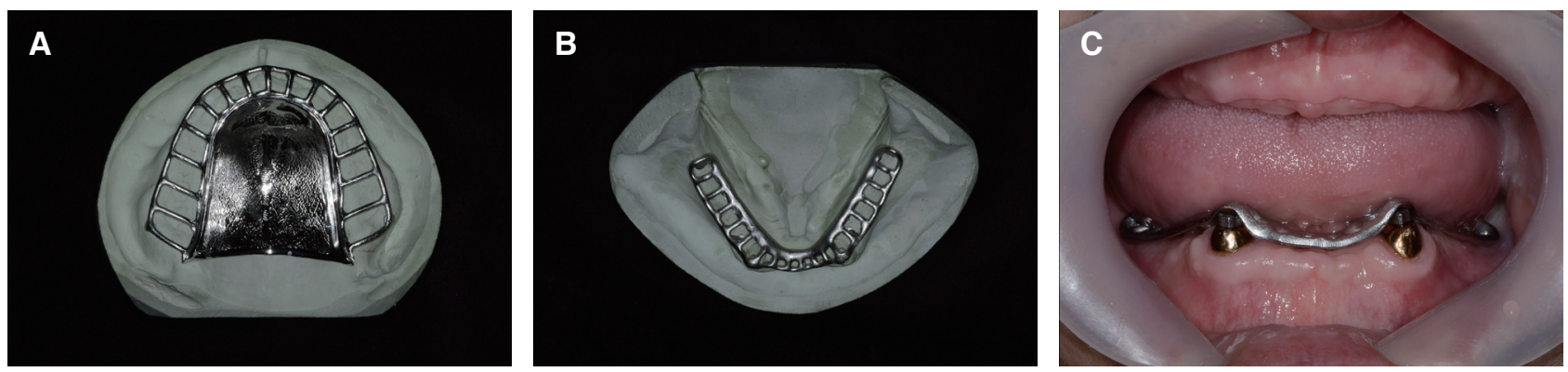

Fig. 5. Metal framework. (A) Metal framework of maxilla, (B), (C) Metal framework of mandible.

였다(Fig. 4). 주모형을 제작하고 금속구조물을 제작하 였다(Fig. 5). 기초상과 교합제를 제작하여 수직교합고경 을 설정하고, 악간관계를 채득한 후, 안궁이전하여 작업 모형을 교합기에 부착하였다(Fig. 6). 인공치아를 배열하 여 양측성 균형교합을 부여하였다. 납의치를 구강 내에 시적 후, 환자는 치아 형태 및 배열에 만족하는지 확인 후 (Fig. 7) 최종 의치를 제작하였다.

기공실 재부착 후, 완성된 최종 의치를 구강내 장착하 여 진료실 재부착을 시행하여 양측성 균형교합을 확인하
였다(Fig. 8). 2주간의 의치 안정기간을 거친 후, female part를 상, 하악 총의치에 자가중합형 아크릴릭 레진 (pattern resin LS, GC Corp.)을 이용하여 직접법으로 연 결하였다(Fig. 9). 구내에서 의치는 잘 유지되었고, 한손 으로도 쉽게 의치의 착탈이 가능하였다. 환자는 편안함 과 심미, 기능적으로 매우 만족하였다. 유지 및 관리를 위 해 정기적으로 내원 중에 있으며, 치료 이후 6개월 간의 임상관찰에서 환자는 심미적, 기능적으로 만족하고 안정 적으로 유지되었다. 

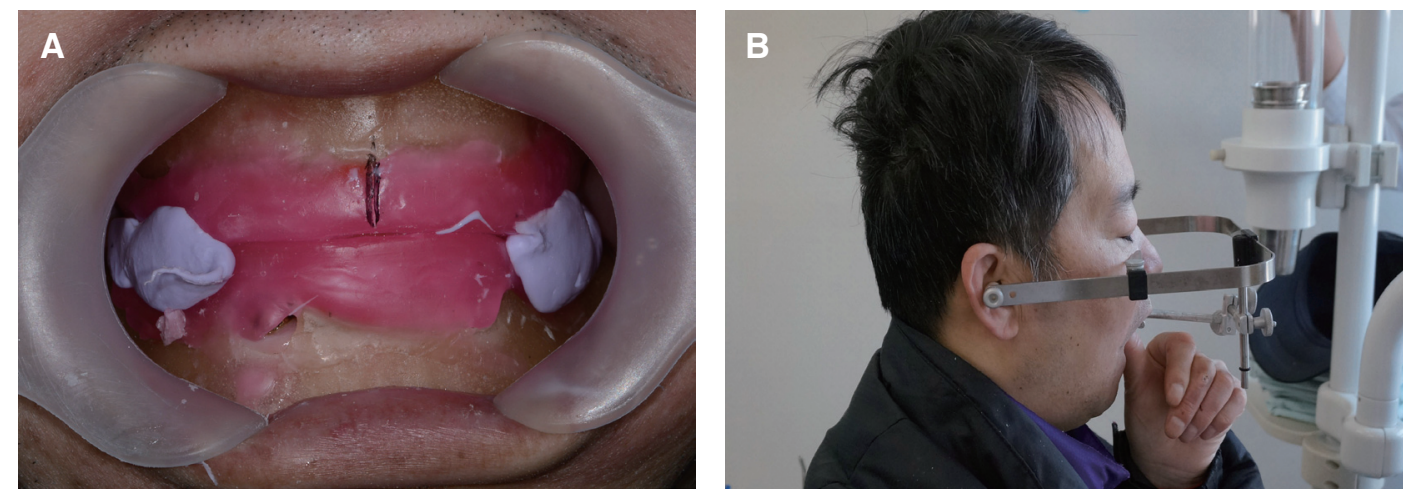

Fig. 6. Maxillomandibular relationship record. (A) VD taking, (B) Facebow transfer.

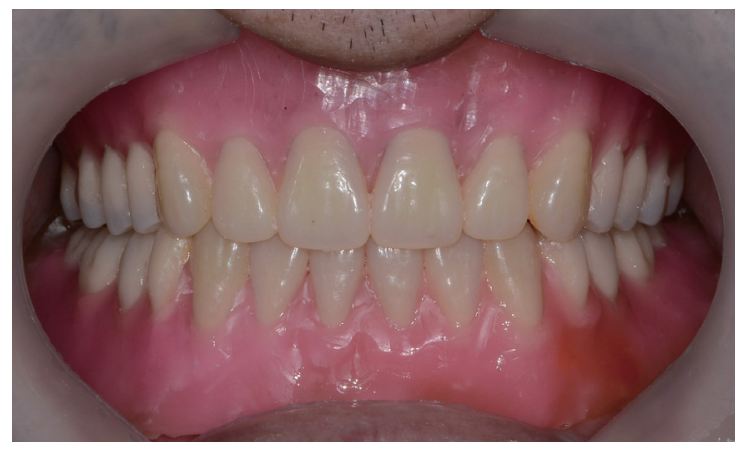

Fig. 7. Wax denture try-in.

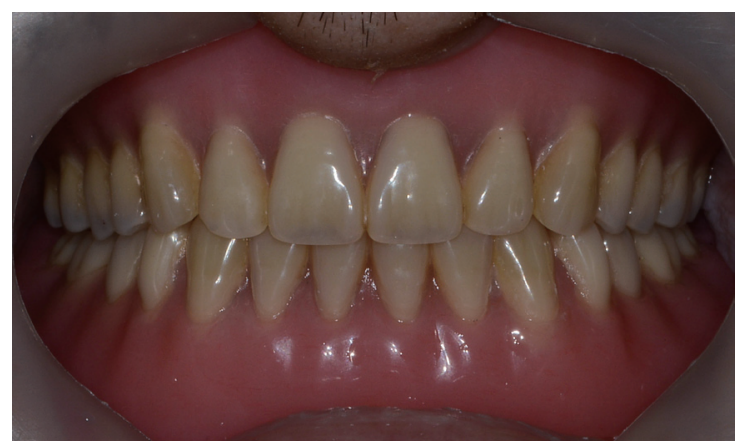

Fig. 8. Definitive denture.

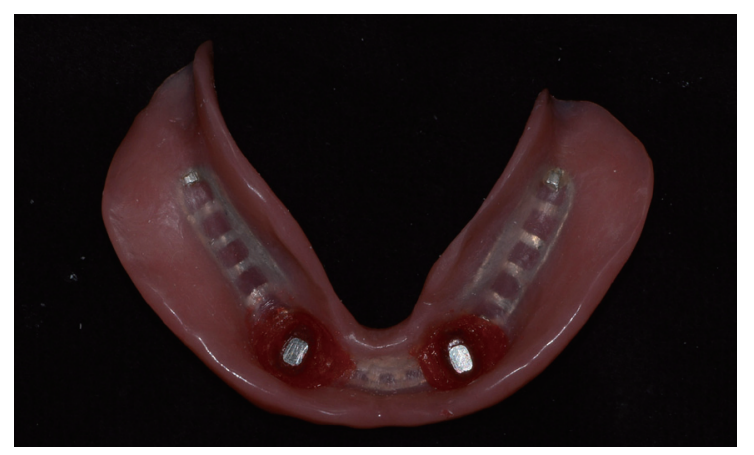

Fig. 9. Overdenture component placement (Magfit EX 600 ${ }^{\circledR}$ ).

\section{고찰}

피개의치 제작 시 어태치먼트 선택은 중요한 과정이다. 임상가는 다양한 어태치먼트 시스템 중에서 환자의 요 구, 유지력, 비용, 효율성, 내구성 등을 고려하여 가장 적 절한 어태치먼트를 선택하게 된다.

치과용 자성 어태치먼트는 피개의치의 유지력을 증 대시키기 위해 치과 보철 분야에서 오랫동안 사용되 어 왔다. 구강 내 magnet의 이점은 다음과 같다. 첫번째 로 지대치에 가해지는 측방 하중을 감소시키는 "stress breaking” 효과를 기대할 수 있다. ${ }^{1}$ 의치의 움직임에 따 른 지대치에 가해지는 하중을 수평적인 것과 수직적인 것 으로 나누어 보았을 때 수직적인 하중 형태에 대해서는 어떠한 유지 장치도 지대치에 유해한 힘을 덜 가할 수 있 지만 수평적인 힘, 즉 측방 하중에 대해서는 다소 지대치 에 유해한 힘을 전달할 수 있다. 자성 어태치먼트는 clasp 이나 konus attachment에 의해 연결되어 있는 지대치보 다 상대적으로 약한 하중이 전달된다. 두번째로 유지력 의 장기 안정성을 들 수 있다. 자성 어태치먼트는 다른 어 태치먼트에 비해 유지력 지속기간이 긴 편이다. ${ }^{4}$ 세번째 로 임상 및 기공 과정의 용이성과 수리의 편이성을 장점 으로 들 수 있다. 네번째로 손 조작이 어려운 고령자나 장애인이 보다 쉽게 의치를 장착, 철거할 수 있으며 완성 의치는 복잡한 형태가 아니기 때문에 환자 자신이나 보 호자에 의한 유지 관리가 용이하다. 마지막으로 다른 어 태치먼트보다 높이가 낮아서 부족한 악간 공간을 가진 환자에게 유용하게 쓰일 수 있고 지대치 간의 경사를 어 느 정도 보완해주고 측방 기능력을 없앨 수 있다. ${ }^{5}$

본 증례에서 사용된 Magfit EX $600^{\circledR}$ (Aichi steel Co., Aichi, Japan)은 $\mathrm{NdFeB}$ 자석을 사용하며, 흡착력은 600 
$\mathrm{gf}$ 로, 이는 클라스프의 유지력과 유사하다. 자석의 형태 는 직사각형의 절단면으로 직경은 $2.8 \times 3.8 \mathrm{~mm}$ 에 높이 는 $1.8 \mathrm{~mm}$ 이고, keeper의 높이는 $1.0 \mathrm{~mm}$ 로 어태치먼트 합계 높이는 $2.8 \mathrm{~mm}$ 이다. ${ }^{6}$

\section{결론}

본 환자는 치료계획 수립 시 환자의 파킨슨 병으로 인 한 혀와 입술의 불수의적 운동으로 의치의 안정성이 부 족하고, 운동장애로 의치의 착탈에 어려움이 있다는 점 을 고려하여 상악 완전 의치, 하악의 잔존치근 피개의치 를 제작하였고, 향상된 의치의 안정성과 높은 환자의 만 족도를 얻게 되었다. 이와 같이 수의 운동이 불일정한 환 자에게 자성 어태치먼트를 이용한 피개의치는 효과적인 치료방법으로 생각되며 유지 및 관리를 위해 주기적인 내 원이 필요하리라 사료된다.

\section{ORCID}

Bo-Young Ma http://ordid.org/0000-0002-8147-056X Byung-Kee Min http://orcid.org/0000-0003-2756-2284

Hong-So Yang http://orcid.org/0000-0002-9138-4817 Sang-Won Park http://orcid.org/0000-0002-9376-9104 Hyun-Pil Lim http://orcid.org/0000-0001-5586-1404 Kwi-Dug Yun http://orcid.org/0000-0002-2965-3967 Chan Park http://orcid.org/0000-0001-5729-5127

\section{References}

1. Kim SU. Implant-supported removable prosthetic treatments with patient focus. Myungmoon; Seoul; 2007.

2. Brånemark PI, Adell R, Breine U, Hansson BO, Lindström J, Ohlsson A. Intra-osseous anchorage of dental prostheses. I. Experimental studies. Scand J Plast Reconstr Surg 1969;3:81-100.

3. Adell R, Lekholm U, Rockler B, Brånemark PI. A 15 -year study of osseointegrated implants in the treatment of the edentulous jaw. Int J Oral Surg 1981;10:387-416.

4. Riley MA, Walmsley AD, Harris IR. Magnets in prosthetic dentistry. J Prosthet Dent 2001;86:13742.

5. Smith GA, Laird WR, Grant AA. Magnetic retention units for overdentures. J Oral Rehabil 1983;10: 481-8.

6. Packer M, Nikitin V, Coward T, Davis DM, Fiske J. The potential benefits of dental implants on the oral health quality of life of people with Parkinson's disease. Gerodontology 2009;26:11-8. 


\section{파킨슨병 환자의 자성 피개의치 수복 증례}

\section{마보영, 민병귀, 양홍서, 박상원, 임현필*, 윤귀덕, 박 찬, 신진호}

전남대학교 치의학전문대학원 보철학교실

총의치 환자에 있어 환자가 만족할 만한 의치의 유지와 안정을 얻는 것은 어려운 일이다. 특히 파킨슨병 등의 전신질환으 로 하악에서 불수의적 운동이나 운동제한이 나타나는 환자에 있어서, 총의치의 기능적 한계는 임상가에게 더욱 더 힘든 문제이다. 이러한 어려움을 극복하기 위해 잔존치근의 보존을 통한 피개의치가 도움이 될 것이다. 본 증례는, 45 세 남성 환자로, 내원 당시 당뇨와 파킨슨 병의 약을 장기 복용 중이었고 우식으로 인해 대다수의 치아를 발치해야 했다. 상악은 총의치, 하악은 2 개의 잔존 치근을 이용한 자성 어태치먼트로 유지와 안정을 증진시킨 피개의치 증례로서, 기능적으로 개선된 보철물을 제작했기에 보고하는 바이다.

(구강회복응용과학지 2016;32(4):301-6)

주요어: 파킨슨병; 피개의치; 자성 어태치먼트 